\title{
Plasma Corticosterone, Insulin and Glucose Changes Induced by Brief Exposure to Isoflurane, Diethyl Ether and $\mathrm{CO}_{2}$ in Male Rats
}

\author{
H. ZARDOOZ ${ }^{1}$, F. ROSTAMKHANI ${ }^{1,2}$, J. ZARINGHALAM $^{1}$, F. FARAJI SHAHRIVAR ${ }^{3}$ \\ ${ }^{1}$ Neuroscience Research Center and Department of Physiology, Faculty of Medicine, Shahid \\ Beheshti University of Medical Sciences, Tehran, Iran, ${ }^{2}$ Applied Neuroscience Research Center, \\ Baqyiatallah (a.s.) University of Medical Sciences, Tehran, Iran, ${ }^{3}$ Research Institute for Endocrine \\ Sciences, Shahid Beheshti University of Medical Sciences, Tehran, Iran
}

Received September 27, 2009

Accepted March 26, 2010

On-line June 9, 2010

\section{Summary}

The impact of anesthetic agents on endocrine and metabolic factors is an important issue. The present study has compared the effects of a short-term exposure to diethyl ether, isoflurane, or $\mathrm{CO}_{2}$ on plasma corticosterone, insulin and glucose concentrations since the duration of anesthetic exposure may have an effect on those factors. Male rats were divided into fed and fasted groups. The experimental rats were briefly exposed to diethyl ether, isoflurane, or $\mathrm{CO}_{2}$ (the degree of anesthesia was identical), while a control group was not exposed to the anesthetics. In the fed rats, diethyl ether exposure increased the levels of plasma glucose. $\mathrm{CO}_{2}$ exposure decreased plasma corticosterone and increased plasma glucose levels. Isoflurane exposure caused no changes in plasma corticosterone, glucose, or insulin levels. In the fasted rats, diethyl ether exposure increased plasma corticosterone and reduced plasma insulin levels. The plasma corticosterone and insulin levels were significantly increased by $\mathrm{CO}_{2}$ exposure. Isoflurane exposure decreased plasma insulin levels. A brief exposure to either diethyl ether or $\mathrm{CO}_{2}$ changed the plasma corticosterone, glucose, and insulin levels in fed and/or fasted rats. However, isoflurane exposure had the least effect on the concentration of these factors in both the fed and fasted states.

\section{Key words}

Anesthesia - Anesthetic agents - Corticosterone - Glucose • Insulin

\section{Corresponding author}

H. Zardooz, Neuroscience Research Center and Department of Physiology, Faculty of Medicine, Shahid Beheshti University of
Medical Sciences, P.O.Box 19615-1178, Tehran, Iran. Fax: (+9821) 22439971. E-mail: homeira_zardooz@yahoo.com

\section{Introduction}

Plasma corticosterone levels in rodents have been considered an important index of stress (Vachon and Moreau 2001, Abelson et al. 2005). However, studies indicate that plasma corticosterone and/or other metabolic parameters such as glucose and insulin concentrations could be affected by factors (e.g. anesthetic agents) other than typical stressors (Winder et al. 1983, Nishiyama et al. 2005).

In one study, rats were exposed to diethyl ether anesthesia. After two minutes of exposure the corneal reflex had disappeared, and the animals were removed and subjected to orbital puncture. The results showed a pronounced increase in plasma corticosterone with a slight increase in plasma glucose (Van Herck et al. 1991). Conversely, with a longer duration of diethyl ether exposure (30 min), fasting plasma glucose and insulin increased significantly in rats starved for $24 \mathrm{~h}$ (AynsleyGreen et al. 1973). In a clinical study on human subjects, $15 \mathrm{~min}$ of anesthesia with isoflurane or sevoflurane caused a significant increase in plasma glucose, but marked decrease of plasma insulin levels (Tanaka et al. 2005). However, a longer duration of anesthesia with isoflurane or sevoflurane $(10 \mathrm{~h})$ caused an increase in plasma cortisol and glucose levels, but had no effect on plasma insulin concentration in human subjects 
(Nishiyama et al. 2005). Zuurbier et al. (2008) obtained the same results in rats following $30 \mathrm{~min}$ of anesthesia with isoflurane or sevoflurane.

Thus, it is evident that exposure to anesthetics may affect experimental results, with differences in the exposure duration leading to further variations. Therefore, the results obtained from relatively short procedures (e.g. retro-orbital blood sampling), which require a short period of exposure to anesthesia, may also be difficult to interpret due to the additional effects of the anesthetic agents on corticosterone or other metabolic parameters such as plasma insulin and glucose.

In this regard, the present study has been designed to further clarify the effects of a brief exposure to commonly used inhaled anesthetics (isoflurane, diethyl ether and $\mathrm{CO}_{2}$, which are also used for short laboratory procedures), on plasma levels of corticosterone, glucose, and insulin. The blood samples were acquired using the retro-orbital puncture technique allowing for a rapid sampling procedure.

\section{Methods}

\section{Animals}

Male Wistar rats weighing 180-210 g (Pasteur Institute, Tehran, Iran) were used throughout this study ( $n=7-9$ per group). The animals were housed two per cage at $22 \pm 2{ }^{\circ} \mathrm{C}$, and the regular $12 \mathrm{~h}$ dark/light cycle was kept constant (light on at $0700 \mathrm{~h}$ and off at $1900 \mathrm{~h}$ ). The animals had access to food and water ad libitum. For the studies using fasted rats, food was withdrawn for $16 \mathrm{~h}$ (from 1630 P.M. to 0830 A.M.) before the start of the experiment. All experimental procedures were conducted in accordance with the Committee's Guidelines and Regulations for Animal Care and were approved by the animal care and use committee of the Shahid Beheshti University of Medical Sciences, Neuroscience Research Center.

The animals were randomly divided into two groups, fed and fasted. Each group was subdivided into two groups, control and experimental. In the control group, blood was obtained without anesthesia, whereas in the experimental group, the animals were exposed to isoflurane, diethyl ether, or $\mathrm{CO}_{2}$. The reduction of respiratory rate (nearly $50 \%$ ) and loss of the righting reflex (a reflex which maintains the animal's normal standing position and head upright) were considered to be signs of deep anesthesia in the experimental group (Yale
University IACUC) ${ }^{1}$. At the end of the experiments, the animals were euthanized by $\mathrm{CO}_{2}$ (NIH Guidelines) ${ }^{2}$.

\section{Open drop method}

The method used to deliver isoflurane or diethyl ether to the rats is described in detail in the policies and guidelines of Institutional Animal Care \& Use Committee (Yale University IACUC). In short, a cotton ball soaked in the exact amount of isoflurane $(1.25 \mathrm{ml} / \mathrm{l})$ or diethyl ether $(2.75 \mathrm{ml} / \mathrm{l})$ was placed in a transparent glass desiccator, under a screen to avoid any skin irritation to the rat caused by a contact with the soaked cotton. Each rat was monitored after being placed inside the desiccator with a tightly closed lid. A reduction in the animal's respiratory rate (nearly $50 \%$ ) and loss of the righting reflex were indicative of a state of deep anesthesia (Yale University IACUC), which occurred nearly 2 min after isoflurane and $4 \mathrm{~min}$ after diethyl ether exposure. The rat was immediately removed from the desiccator as soon as these signs were observed. If no response to a toe pinch was seen, the retro-orbital blood sampling was performed immediately after removing the rat from the desiccator.

In order to anesthetize the rats with $\mathrm{CO}_{2}$, a vacuum desiccator connected to a $\mathrm{CO}_{2}$ cylinder was used. After placing the rat inside the desiccator, $\mathrm{CO}_{2}(100 \%)$, with a constant pressure $\left(50 \mathrm{~kg} / \mathrm{cm}^{2}\right)$ and flow rate of $71 / \mathrm{min}$, was dispersed into the desiccator. The rat was removed from the desiccator once the signs of deep anesthesia (in about $1 \mathrm{~min}$ from starting $\mathrm{CO}_{2}$ flow) were observed. The blood sampling procedure followed immediately.

One milliliter of blood was collected in an Eppendorf tube containing $5 \mu \mathrm{l}$ heparin $(5000 \mathrm{IU} / \mathrm{ml})$ (Chalkley et al. 2002), and centrifuged at $3000 \times \mathrm{g}$ for 5 min (Toleikis and Godin 1995). The plasma was collected and stored at $-74{ }^{\circ} \mathrm{C}$ for measurements of corticosterone, glucose, and insulin.

\section{Drugs}

Isoflurane (Nicholas Piramal, UK), diethyl ether (Merck, Germany), and $\mathrm{CO}_{2}$ in gaseous form (IranOxygen Co.), were used as inhaled anesthetics.

\footnotetext{
${ }^{1}$ Policies and guidelines, Institutional Animal Care \& Use Committee (IACUC). Yale University. Last Modified: November 21, 2005.

2 Guidelines for euthanasia of rodents using carbon dioxide, NIH Guidelines, December 9, 2001.
} 
Table 1. Plasma corticosterone concentrations in fed and fasted rats of control group (non-anesthetized) and in rats under isoflurane, diethyl ether and $\mathrm{CO}_{2}$ anesthesia.

\begin{tabular}{|c|c|c|c|c|}
\hline \multirow[t]{2}{*}{ Group } & \multicolumn{4}{|c|}{ Corticosterone concentration (nmol/ml) } \\
\hline & Control & Isoflurane & Diethyl ether & $\mathrm{CO}_{2}$ \\
\hline Fed & $1.85 \pm 0.21$ & $1.50 \pm 0.06$ & $1.59 \pm 0.10$ & $0.93 \pm 0.10^{* * * q}$ \\
\hline Fasted & $1.66 \pm 0.22$ & $1.84 \pm 0.14$ & $2.65 \pm 0.17^{* * *} \S$ & $2.18 \pm 0.15^{*}$ \\
\hline
\end{tabular}

Data are mean \pm S.E.M. ( $n=7-9$ per group). $* \mathrm{P}<0.05$, $* * * \mathrm{P}<0.001$, significant difference versus control; ${ }^{\Uparrow} \mathrm{P}<0.001$, significant difference versus diethyl ether and isoflurane anesthesia; ${ }^{\S} \mathrm{P}<0.001$, significant difference versus isoflurane anesthesia.

Table 2. Plasma glucose concentrations in fed and fasted rats of control group (non-anesthetized) and in rats under isoflurane, diethyl ether and $\mathrm{CO}_{2}$ anesthesia.

\begin{tabular}{|c|c|c|c|c|}
\hline \multirow[t]{2}{*}{ Group } & \multicolumn{4}{|c|}{ Glucose concentration (mg/dl) } \\
\hline & Control & Isoflurane & Diethyl ether & $\mathrm{CO}_{2}$ \\
\hline Fed & $105.58 \pm 4.03$ & $118.17 \pm 2.02$ & $144.96 \pm 4.61^{* * * \Psi q}$ & $124.28 \pm 11.13^{*}$ \\
\hline Fasted & $88.03 \pm 2.09$ & $92.83 \pm 4.08$ & $98.11 \pm 3.25$ & $96.97 \pm 4.98$ \\
\hline
\end{tabular}

Data are mean \pm S.E.M. ( $\mathrm{n}=8-9$ per group). $* \mathrm{P}<0.05$, *** $\mathrm{P}<0.001$ significant difference versus control; ${ }^{4} \mathrm{P}<0.01,{ }^{\natural} \mathrm{P}<0.001$ significant difference versus $\mathrm{CO}_{2}$ and isoflurane anesthesia, respectively.

\section{Hormone assessments}

Plasma corticosterone was analyzed by the corticosterone Elisa kit (DRG, Germany). Plasma glucose was assessed using a glucose oxidase method (Pars Azmoon, Iran). Plasma insulin was determined by the rat insulin Elisa kit (Mercodia, Sweden).

\section{Statistical analyses}

All data are expressed as the mean \pm S.E.M. One-way and two-way analysis of variance were performed and supported by an LSD test. $\mathrm{P}<0.05$ value was considered to be statistically significant.

\section{Results}

\section{Plasma corticosterone levels in fed and fasted animals}

Plasma corticosterone levels decreased significantly in the fed group under $\mathrm{CO}_{2}$ anesthesia compared with the control, isoflurane, and diethyl ether groups $(\mathrm{P}<0.001)$ (Table 1$)$.

In the fasted animals, diethyl ether increased corticosterone levels significantly as compared to the controls and isoflurane-treated animals $(\mathrm{P}<0.001)$. Exposure to $\mathrm{CO}_{2}$ also increased plasma corticosterone levels compared with the fasted control rats $(\mathrm{P}<0.05)$ (Table 1).

Moreover, a two-way ANOVA showed no significant difference between fed and fasted rats of the control group, whereas there were significant differences $(\mathrm{P}<0.001)$ between fed and fasted rats in each group subjected to the same anesthetic agents.

\section{Plasma glucose levels in fed and fasted animals}

A significant increase in plasma glucose levels was observed in the fed rats under $\mathrm{CO}_{2}(\mathrm{P}<0.05)$ and diethyl ether $(\mathrm{P}<0.001)$ anesthesia compared with the controls (Table 2). In the fed group, diethyl ether anesthesia caused a significant elevation of plasma glucose concentrations as compared to isoflurane $(\mathrm{P}<0.001)$ and $\mathrm{CO}_{2}(\mathrm{P}<0.01)$ anesthesia (Table 2).

No significant difference was observed between all groups of fasted rats with respect to plasma glucose concentrations (Table 2).

However, plasma glucose concentrations in fed rats were significantly higher than those in the fasted animals in all experimental groups $(\mathrm{P}<0.001)$.

\section{Plasma insulin levels in fed and fasted animals}

Plasma insulin levels were increased significantly in the fed groups under diethyl ether and $\mathrm{CO}_{2}$ anesthesia as compared to the isoflurane group $(\mathrm{P}<0.001)$ (Table 3).

In the fasted groups of rats, the plasma insulin was significantly increased under $\mathrm{CO}_{2}$ anesthesia, 
Table 3. Plasma insulin concentrations in fed and fasted rats of control group (non-anesthetized) and in rats under isoflurane, diethyl ether and $\mathrm{CO}_{2}$ anesthesia.

\begin{tabular}{|c|c|c|c|c|}
\hline \multirow[t]{2}{*}{ Group } & \multicolumn{4}{|c|}{ Insulin concentration $(\mu \mathrm{g} / \mathrm{l})$} \\
\hline & Control & Isoflurane & Diethyl ether & $\mathrm{CO}_{2}$ \\
\hline Fed & $1.03 \pm 0.09$ & $0.71 \pm 0.11$ & $1.51 \pm 0.3^{\pi}$ & $1.42 \pm 0.18^{\pi}$ \\
\hline Fasted & $0.71 \pm 0.12$ & $0.29 \pm 0.08^{* *}$ & $0.32 \pm 0.06^{* *}$ & $1.33 \pm 0.22^{* * *} \S$ \\
\hline
\end{tabular}

Data are mean \pm S.E.M. ( $\mathrm{n}=7-9$ per group). ${ }^{* *} \mathrm{P}<0.01, * * * \mathrm{P}<0.001$ significant difference versus control; ${ }^{\circledR} \mathrm{P}<0.001$, significant difference versus isoflurane anesthesia; ${ }^{\S} \mathrm{P}<0.001$ significant difference versus isoflurane and diethyl ether anesthesia.

compared to the control, diethyl ether, and isoflurane groups of animals $(\mathrm{P}<0.001)$ (Table 3$)$. Compared to the control rats, a significant decrease in plasma insulin concentrations was observed under isoflurane and diethyl ether anesthesia in the fasted state $(\mathrm{P}<0.01)$ (Table 3$)$.

A two-way ANOVA showed a significant difference between the fed and fasted rats in the isoflurane and diethyl ether groups $(\mathrm{P}<0.001)$.

\section{Discussion}

The main objective of the present study was to further clarify the effects of a brief exposure to inhaled anesthetics. The results of this study indicated that a brief exposure to diethyl ether and $\mathrm{CO}_{2}$ may cause significant changes in plasma corticosterone, insulin, and glucose concentrations both in fed and fasted rats compared to isoflurane. These results have highlighted the possibility of changes in endocrine and metabolic factors, even under brief exposure to these anesthetics.

In this study, the control (non-anesthetized) group values may be affected by the stress imposed by the procedure (e.g. handling and blood sampling). However, since this intervention could not be avoided, we considered this group as the control group.

Diethyl ether as an anesthetic agent causes noticeable stress responses (Van Herck et al. 1991) and has even been used as an actual stressor (Hashimoto et al. 1989). In contrast to the results of the current study, plasma concentrations of corticosterone and glucose were elevated concomitantly under diethyl ether anesthesia in other studies (Van Herck et al. 1991, De Haan et al. 2002). However, the difference may be due to the experimental design (e.g. the duration and type of exposure and also the volume of the diethyl ether). On the other hand, fasting may cause plasma corticosterone elevation (Woodward et al. 1991, Chang et al. 2002), but it is also dependent on the fasting duration (Bojková et al.
2006). It appears that fasting, even for a short duration, combined with diethyl ether, could markedly increase plasma corticosterone levels. Moreover, the significant reduction in plasma glucose levels in the fasted control rats compared to the fed animals may be attributable to the effect of fasting (Guezennec et al. 1988). AynsleyGreen et al. (1973) showed that in rats that were fasted for $24 \mathrm{~h}$, the fasting plasma glucose and insulin levels rose significantly following a $30 \mathrm{~min}$ exposure to diethyl ether using a vaporizer, which contradicts our results. One explanation for this difference could be the time of anesthetic exposure, which was shorter in our study (4 min versus $30 \mathrm{~min}$ ). This finding shows that the effects of diethyl ether on plasma insulin and glucose levels could be different according to the length of exposure to the anesthetic. Another possible explanation is that plasma corticosterone elevation following diethyl ether exposure in the fasted rats may actually inhibit insulin secretion (Billaudel and Shutter 1982). In the fed rats, increased plasma glucose concentrations under diethyl ether exposure, without significant change in corticosterone, could be the result of an increase in the sympathoadrenal system activity (Carruba et al. 1987).

An increase in plasma corticosterone levels in the fasted rats under $\mathrm{CO}_{2}$ anesthesia is in agreement with the results of an experiment which was done by Altholtz et al. (2006) in rats using the same anesthetic. The insulin elevation in the same group of rats was observed to be euglycemia due to the acute hyperglycemic effect of corticosterone secretion induced by the $\mathrm{CO}_{2}$. However, in the fed rats under $\mathrm{CO}_{2}$ anesthesia, despite a reduction in plasma corticosterone concentration, the plasma glucose levels increased. This increment of plasma glucose may be due to the increased sympathoadrenal system activity caused by $\mathrm{CO}_{2}$ exposure (Winder et al. 1983).

Under a brief exposure to isoflurane, the lack of changes in plasma corticosterone is in contrast with previous studies which indicated that long-term duration 
of isoflurane exposure may increase plasma cortisol in humans (Nishiyama et al. 2005) and plasma corticosterone in rats (Altholtz et al. 2006). It appears that anesthetic exposure duration is the reason for the differences between our results and those from previous studies. In contrast to our study, Saha et al. (2005) have demonstrated an increase in plasma glucose concentration in fed animals under isoflurane anesthesia, which may be due to the increase in plasma norepinephrine as well as increased growth hormone levels induced by isoflurane (Diltoer and Camu 1988). Tanaka et al. (2005) have also shown a plasma glucose increase and decrease in plasma insulin under isoflurane or sevoflurane anesthesia in patients subjected to minor surgery. The decrease in fasting plasma insulin, which was also observed in the present study, may be due to the inhibition of glucosestimulated insulin release induced by isoflurane exposure (Desborough et al. 1993) and the fasting state (Pequignot et al. 1980).
In conclusion, the results from this study indicate that the measured metabolic parameters are dependent on anesthetics and fed or fasted state. Therefore, the results of our study suggest that the metabolic profile obtained in each situation may be used as a reference for possible artifacts induced by any experimental approach using these anesthetics.

\section{Conflict of Interest}

There is no conflict of interest.

\section{Acknowledgements}

This work was supported by a grant from Neuroscience Research center, Shahid Beheshti University of Medical Sciences and Applied Neuroscience Research center, Baqyiatallah (a.s.) University of Medical Sciences. The authors would like to express their gratitude to Ms. Mansoureh Farahmand for her help in preparation of the manuscript.

\section{References}

ABELSON KS, ADEM B, ROYO F, CARLSSON HE, HAU J: High plasma corticosterone levels persist during frequent automatic blood sampling in rats. In Vivo 19: 815-819, 2005.

ALTHOLTZ LY, FOWLER KA, BADURA LL, KOVACS MS: Comparison of the stress response in rats to repeated isoflurane or $\mathrm{CO}_{2}: \mathrm{O}_{2}$ anesthesia used for restraint during serial blood collection via the jugular vein. $J \mathrm{Am}$ Assoc Lab Anim Sci 45: 17-22, 2006.

AYNSLEY-GREEN A, BIEBUYCK JF, ALBERTI KG: Anesthesia and insulin secretion: the effects of diethyl ether, halothane, pentobarbitone sodium and ketamine hydrochloride on intravenous glucose tolerance and insulin secretion in the rat. Diabetologia 9: 274-281, 1973.

BILLAUDEL B, SUTTER BC: Immediate in vivo effect of corticosterone on glucose-induced insulin secretion in the rat. $J$ Endocrinol 95: 315-320, 1982.

BOJKOVÁ B, MARKOVÁ M, AHLERSOVÁ E, AHLERS I, ADAMEKOVÁ E, KUBATRA P: Metabolic effects of prolonged melatonin administration and short-term fasting in laboratory rats. Acta Vet Brno 75: 21-32, 2006.

CARRUBA MO, BONDIOLOTTI G, PICOTTI GB, CATTERUCCIA N, DA PRADA M: Effects of diethyl ether, halothane, ketamine and urethane on sympathetic activity in the rat. Eur J Pharmacol 134: 15-24, 1987.

CHALKLEY SM, HETTIARACHCHI M, CHISHOLM DJ, KRAEGEN EW: Long-term high-fat feeding leads to severe insulin resistance but not diabetes in Wistar rats. Am J Physiol 282: E1231-E1238, 2002.

CHANG LL, KAU MM, WUN WS, HO LT, WANG PS: Effects of fasting on corticosterone production by zona fasciculata-reticularis cells in ovariectomized rats. J Invest Med 50: 86-94, 2002.

DE HAAN M, VAN HERCK H, TOLBOOM JB, BEYNEN AC, REMIE R: Endocrine stress response in jugular-vein cannulated rats upon multiple exposure to either diethyl-ether, halothane- $\mathrm{O}_{2}-\mathrm{N}_{2} \mathrm{O}$ or sham anaesthesia. $L a b$ Anim 36: 105-114, 2002.

DESBOROUGH JP, JONES PM, PERSAUD SJ, LANDON MJ, HOWELL SL: Isoflurane inhibits insulin secretion from isolated rat pancreatic islets of Langerhans. Br J Anaesth 71: 873-876, 1993.

DILTOER M, CAMU F: Glucose homeostasis and insulin secretion during isoflurane anesthesia in humans. Anesthesiology 68: 880-886, 1988. 
GUEZENNEC CY, NONGLATON J, SERRURIER B, MERINO D, DEFER G: Hormonal and metabolic response to physical exercise, fasting and cold exposure in the rat. Effects on ketogenesis in isolated hepatocytes. Eur Appl Physiol 57: 114-119, 1988.

HASHIMOTO K, MURAKAMI K, TAKAO T, MAKINO S, SUGAWARA M, OTA Z: Effect of acute ether or restraint stress on plasma corticotropin releasing hormone, vasopressin and oxytocin levels in the rat. Acta Med Okayama 43: 161-167, 1989.

NISHIYAMA T, YAMASHITA K, YOKOYAMA T: Stress hormone changes in general anesthesia of long duration: isoflurane-nitrous oxide vs sevoflurane-nitrous oxide anesthesia. J Clin Anesth 17: 586-591, 2005.

PEQUIGNOT JM, PEYRIN L, PERES G: Catecholamine-fuel interrelationships during exercise in fasting men. $J$ Appl Physiol 48: 109-113, 1980.

POMPLUN D, MOHLIG M, SPRANGER J, PFEIFFER AFH, RISTOW M: Elevation of blood glucose following anesthetic treatment in C57BI/6 mice. Horm Metab Res 36: 67-69, 2004.

SAHA JK, XIA J, GRONDIN JM, ENGLE SK, JAKUBOWSKI JA: Acute hyperglycemia induced by ketamine/xylazine anesthesia in rats: mechanisms and implications for preclinical models. Exp Biol Med 230: 777-784, 2005.

TANAKA T, NABATAME H, TANIFUJI Y: Insulin secretion and glucose utilization are impaired under general anesthesia with sevoflurane as well as isoflurane in a concentration-independent manner. $J$ Anesth 19: 277-281, 2005.

TOLEIKIS PM, GODIN DV: Alteration of antioxidant status in diabetic rats by chronic exposure to psychological stressors. Pharmacol Biochem Behav 52: 355-366, 1995.

VACHON P, MOREAU JP: Serum corticosterone and blood glucose in rats after two jugular vein blood sampling methods: comparison of the stress response. Contemp Top Lab Anim Sci 40: 22-24, 2001.

VAN HERCK H, BAUMANS V, DE BOER SF, VAN DER GUGTEN J, VAN WOERKOM AB, BEYNEN AC: Endocrine stress response in rats subjected to singular orbital puncture while under diethyl-ether anesthesia. Lab Anim 25: 325-329, 1991.

WINDER WW, FULLER EO, CONLEE RK: Adrenal hormones and liver cAMP in exercising rats - different modes of anesthesia. J Appl Physiol 55: 1634-1636, 1983.

WOODWARD CJH, HERVEY GR, OAKEY RE, WHITAKER EM: The effects of fasting on plasma corticosterone kinetics in rats. Br J Nutr 66: 117-127, 1991.

ZUURBIER CJ, KEIJZERS PJM, KOEMAN A, VAN WEZEL HB, HOLLMANN MW: Anesthesia's effects on plasma glucose and insulin and cardiac hexokinase at similar hemodynamics and without major surgical stress in fed rats. Anesth Analg 106: 135-142, 2008. 